\title{
Acumulación de viviendas por parte de los bancos a través de los desahucios: geografía de la desposesión de vivienda en Cataluña
}

Aaron Gutiérrez. Universidad Rovira i Virgili, Vilaseca, España.

Sònia Vives-Miró. Universidad de Santiago de Compostela, Santiago de Compostela, España.

RESUMEN | La extensión de los desahucios desde 2008 es una manifestación de las consecuencias del modelo inmobiliario y financiero español, y también el mecanismo necesario para mantener la lógica de este modelo de acumulación por desposesión. Así, los desahucios por ejecución hipotecaria están alimentando un proceso de concentración de vivienda en manos de la banca. El trabajo aborda el análisis de este proceso a través del estudio de la concentración de la propiedad y la emergencia de unos nuevos grandes propietarios de vivienda y de sus lógicas territoriales en Cataluña. Concluimos argumentando que las llamadas soluciones a la crisis han supuesto la intensificación del desarrollo geográfico desigual mediante la apropiación de rentas urbanas a través de la desposesión de vivienda. Mientras Bbva y Bankia son las entidades que han concentrado más ayudas públicas, son también las que más vivienda vacía proveniente de desahucios acumulan, concentrándose, además, en los barrios más precarizados.

PALABRAS CLAVE | desigualdades regionales, mercado inmobiliario, vivienda.

ABSTRACT | The extension of evictions since 2008 is a manifestation of the consequences of the Spanish real estate and financial model, as well as a needed mechanism to maintain the logic of the model of accumulation by dispossession. The evictions due to foreclosures are fuelling a process of accumulation of housing in hands of bank entities. This paper studies the process of ownership concentration and the emergence of new grand landlords and, secondly, develops an analysis of the territorial logics of this process in Catalonia. We conclude by arguing that the so-called solutions to the crisis have led to the intensification of uneven geographical development through the appropriation of urban incomes through dispossession housing. In this sense, while BBVA and Bankia are the entities that have concentrated most public funds, they are also the ones that have accumulated most empty housing units acquired by foreclosures. These housing units are concentrated in the most precarious neighborhoods.

KEYWORDS | regional inequalities, real estate market, housing. 


\section{Introducción}

A la hipertrofia inmobiliaria, el boom urbanizador, la burbuja de precios de la vivienda, la expansión del crédito hipotecario y sobreendeudamiento familiar experimentados en España durante la década 1997-2007 les ha seguido la posterior caída de precios, la crisis hipotecaria, el rescate bancario, las políticas de austeridad y la proliferación de los desahucios. El mercado inmobiliario español ha dibujado el ciclo completo de alza y caída, propio de la lógica de la "urbanización del capital" y que permite mantener y alimentar los procesos de acumulación por desposesión (Harvey, 2003). Así, la financiarización del entorno construido, y particularmente de la vivienda, ha intensificado a su vez los procesos específicos de acumulación de rentas urbanas por desposesión de vivienda (Aalbers, 2008; Gotham, 2009). No obstante, la solución espacial (spatial fix) española (López \& Rodríguez, 2011) se ha traducido en el sobreendeudamiento y la precarización masiva de las clases menos privilegiadas y la actual oleada de desahucios, tanto por impago de alquiler como por ejecuciones hipotecarias.

Existe ya una abundante literatura que analiza las raíces de este fenómeno en España desde diferentes disciplinas y perspectivas (Coq-Huelva, 2013; Gutiérrez \& Delclòs, 2016; Méndez, Abad \& Plaza, 2014; Vives-Miró, González-Pérez \& Rullan, 2015), coincidiendo en apuntar la proliferación de los desahucios y desposesión de vivienda como la manifestación más evidente de las implicaciones del modelo inmobiliario y financiero español. Desde el inicio de la crisis inmobiliaria se han desbocado las ejecuciones hipotecarias (más de 600.000 entre 2008 y 2015). Pero aunque los desahucios sean el fenómeno más visible dentro de la desposesión de vivienda, solo son la punta del iceberg. De hecho, más allá de dichos desahucios, las políticas implantadas desde la crisis están intensificando el cercamiento a la vivienda (Hodkinson, 2012) en España.

En este contexto, se produce la paradoja de un intenso cercamiento a la vivienda que convive con un gran stock de viviendas vacías y de segunda residencia. Sin embargo, desde el inicio de la crisis no solo se ha ampliado el proceso de desposesión de vivienda, sino también el de acumulación de viviendas vacías. Así, a través de los desahucios derivados de ejecuciones hipotecarias, las entidades financieras están emergiendo como nuevos agentes de acumulación de viviendas vacías, ampliando así su rol en el mercado inmobiliario. Todo ello ha sucedido en un contexto en que, además, el sector financiero español ha recibido grandes cantidades de capital a través del rescate bancario.

Este texto analiza la acumulación de vivienda vacía por parte de las entidades financieras a través de procesos de ejecución hipotecaria que han derivado en desahucios. También estudia y caracteriza la distribución espacial de estas viviendas vacías como una evidencia del desigual desarrollo de la desposesión de vivienda en Cataluña. Así, el artículo pretende dar respuesta a las siguientes preguntas de investigación, estructuradas en dos bloques:

1. ¿Qué cantidad de vivienda vacía acumulan los bancos? ¿Qué entidades concentran un mayor volumen? ¿Cómo y por qué se ha desarrollado este proceso? 
2. ¿A qué espacialidad responde esta vivienda propiedad de la banca? ¿Existen territorios especialmente afectados por este proceso?

Para responder a estas preguntas, en primer lugar, se lleva a cabo un repaso a las raíces del fenómeno: la variedad española de la finaciarización. En segundo lugar, se presenta la fuente de datos del trabajo y sus particularidades, así como la metodología utilizada. A continuación, se detallan los resultados obtenidos, los cuales permiten una caracterización inédita del parque de vivienda en manos de la banca, tanto en relación con la identificación y dimensionado de los nuevos grandes propietarios de vivienda, como con su espacialidad. Finalmente, se subrayan nuevas especificidades de las formas de financiarización de la vivienda.

\section{La variedad española de financiarización y cercamiento del entorno construido}

Que España sea uno de los países más sacudidos por la actual crisis financiera global no es fruto del azar o una fatalidad no prevista, sino que entra en la lógica de su modelo basado en la deuda inmobiliaria (López \& Rodríguez, 2010; Naredo, 2010), que tras el pinchazo de la burbuja se debate entre la reestructuración o su fin. Se trata de un rasgo común entre los países del sur de Europa, Irlanda y Estados Unidos (Cano, Etxezarreta, Dol \& Hoekstra, 2013), los cuales han afrontado una crisis de mayor calado. Una crisis, por supuesto padecida por las clases bajas y medias, ya que para las élites representa nuevas puertas y oportunidades de negocios. No obstante, pese a tener unos mismos fundamentos, cada uno de estos territorios ha desarrollado un modelo propio. Las variedades de financiarización, el papel que ha jugado el Estado en la construcción y el sostenimiento del modelo, y el papel de sus agentes, especialmente los financieros e inmobiliarios, son específicos de cada región.

En el caso del "modelo español", las estrategias financieras que promovieron la articulación de la burbuja han sido la especialización en la construcción y el turismo a través del desmantelamiento de gran parte del aparato productivo (López \& Rodríguez, 2011). Ello tiene sus orígenes en las políticas económicas impulsadas durante el régimen franquista, y se consolidó como modelo hegemónico a partir de los años ochenta mediante la entrada de España en la Unión Europea. Lo que caracteriza el modelo es la inversión masiva de capitales — sobre todo europeos, aunque también espańoles - en el circuito secundario (Harvey, 1982), consolidado como spatial fix (Harvey, 2003), desencadenando lo que se ha llamado también tsunami urbanizador (Fernández Durán, 2009) o hipertrofia inmobiliaria (Gutiérrez \& Delclòs, 2015).

A partir de mediados de los noventa se desplegaron las estrategias de financiarización y de creación de liquidez a través del entorno construido (Coq-Hueva, 2013; Gotham, 2009). De esta manera, en este último ciclo alcista (1995-2007) no solo se ha acelerado el modelo de urbanismo expansivo (Rullan, 2012), sino que, fundamentalmente, al incrementarse las rentas potenciales (Smith, 2012), es decir, las expectativas de apropiación de renta, lo que se acaeció fue una revalorización 
del patrimonio inmobiliario (Naredo, 2009). En otras palabras, se "alimentó una escalada de precios que terminó movilizando la inversión de las clases medias y la afluencia de capital foráneo, tanto para adquisición directa de paquetes de inmuebles como a través de fondos de inversión" (Sevilla-Buitrago, 2015, p. 38).

Dicho modelo no hubiera funcionado sin dos de sus piezas clave: el Estado y las entidades financieras. El Estado desempeńó un rol fundamental potenciando estas lógicas mediante la articulación de la legislación necesaria. La liberalización del mercado de las hipotecas desde 1992 promovió la expansión del crédito hipotecario y promocionó la titulización. Además, una particularidad relevante de la ley hipotecaria española es que, a diferencia de lo que ocurre en muchos otros estados, como es el caso de los Estados Unidos, en España, pese a que el banco se apropie de su vivienda y ser desahuciados, los titulares del crédito hipotecario aún acumulan deudas con este si el valor de mercado en el momento de ser ejecutado el inmueble es inferior a la deuda pendiente de pago (más los respectivos intereses y tasas judiciales). A continuación, la liberalización del suelo a partir de 1994 redujo la mayor parte de las restricciones que la planificación urbana tenía en la urbanización e implantó una valoración del suelo a partir de sus expectativas de renta. La política de vivienda y su fiscalidad ha estado basada en la reducción de la vivienda pública, la marginación de la vivienda de alquiler y las deducciones fiscales por compra de vivienda. Sin embargo, el desarrollo de la legislación fue de la mano de un reescalamiento de la espacialidad del Estado (Brenner, 2003) y el establecimiento de unas fuertes redes de poder entre los inversores, políticos locales y cajas de ahorro, las cuales han derivado, frecuentemente, en prácticas clientelares y casos de corrupción (Naredo, 2010).

Por su parte, las entidades financieras, especialmente las cajas de ahorros, han resultado otro agente clave, financiando la compra del suelo y la construcción a promotores y la adquisición de la vivienda a los compradores, gracias a sus tipos de interés especialmente bajos (García-Montalvo, 2008). En primer lugar, han financiado los promotores y los proyectos de las políticas locales. De hecho, la estructura de propiedad de las cajas de ahorros españolas se ha caracterizado por contener un gran número de cargos nombrados directamente por los gobiernos locales y regionales, con control directo y con conexiones en los partidos políticos. Este ha resultado uno de los puntos clave en algunos casos de corrupción. En segundo lugar, han financiado a las clases medias a través del crédito hipotecario para la adquisición de vivienda en propiedad, ejerciendo así un papel fundamental en el llamado capitalismo popular y en la constitución del efecto riqueza (Naredo, 2010). Entre 1998 y 2005, la disminución de los tipos de interés, la reducción del diferencial sobre el Euribor, el alargamiento del plazo de devolución de las hipotecas, la mayor flexibilidad en el retorno del capital prestado, así como la concesión de préstamos por importes más próximos al precio de la vivienda e, incluso en bastantes casos, superiores a él, permitieron una impresionante expansión del crédito hipotecario, incrementando la capacidad de endeudamiento de las familias (Bernardos, 2009). Así, la deuda hipotecaria se multiplicó por doce durante el periodo 1995-2007, pasando de 24.000 millones de euros a 300.000 millones de euros corrientes (López \& Rodríguez, 2010, p. 190). Asimismo, en la formación de la burbuja española cabe 
destacar también el rol de la banca alemana y francesa. Esta jugó un papel importante en la reducción de los tipos de interés, concediendo grandes cantidades de capital a la banca española, que acabó financiando la burbuja inmobiliaria (Donat, 2014). Por ello, el rescate español, más allá de sanear las entidades españolas, permite garantizar la recuperación de este capital concedido (Sevilla-Buitrago, 2015).

Más allá de la expansión de los créditos a promotores y a familias, una característica fundamental para entender la variedad española de financiarización es la expansión de la titulización, desarrollada a partir de la promulgación de la ley de 1992. Gran parte de estas titulizaciones están respaldadas por títulos residenciales (Residential Mortgage-Backed Security [RMBs]) (Ibáñez-Velasco, 2014), de forma que en un escenario de expansión de RMBs, la vivienda deviene una pieza central de la inversión financiera.

En definitiva, el régimen de acumulación español se ha basado en la revalorización inmobiliaria y la demanda de vivienda en propiedad mediante el endeudamiento generalizado, un modelo que ha significado una clara apuesta por el régimen de tenencia en propiedad. Así, ya durante el franquismo y los años setenta del siglo $\mathrm{xx}$, la vivienda social se utilizó como forma masiva de potenciar el acceso a la vivienda en propiedad de las clases obreras y la formación de un sector de la construcción fuerte. A partir de mediados de los ochenta, la articulación del acceso a vivienda en propiedad a través del endeudamiento supuso que el Estado dejara de invertir de manera directa en el mercado de la vivienda y que lo hiciera, preferentemente, de manera indirecta a través de la fiscalidad (López \& Rodríguez, 2010). Así fue como, entre otras medidas, se implantó el llamado "decreto Boyer", Real Decreto Ley 2/1985, de 30 de abril, sobre medidas de política económica, que liberalizaba el mercado del alquiler urbano y ampliaba las desgravaciones de propiedad de vivienda desde el 15\% al 17\%, incluyendo las no principales. Mientras en los años cincuenta del siglo xx la vivienda en alquiler representaba más del $50 \%$ del total, cinco décadas más tarde, en la primera década del siglo xxI, más del $80 \%$ de la población ya vivía en régimen de propiedad.

A partir del estallido de la burbuja inmobiliaria en 2007 y en paralelo a la crisis de la Eurozona, el "modelo español” mostró sus síntomas de agotamiento. En este contexto, y bajo el pretexto de asegurar la estabilidad financiera en Europa, se han ido implantando medidas dirigidas a recapitalizar los bancos y controlar las deudas estatales a través de un volumen total de ayudas públicas de 3,8 billones de euros en 28 de los Estados Miembros (el 31,4\% del pib de la uE) (Comisión Nacional de los Mercados y la Competencia [CNMC], 2015). España fue uno de los países rescatados por la UE en 2012, consumando el trasvase de la deuda del sector privado al público, es decir, socializando las pérdidas y asegurando la satisfacción de las cantidades prestadas a los bancos europeos.

En España, la desposesión de vivienda que ha acarreado este modelo se ha materializado, especialmente, mediante las ejecuciones hipotecarias y los desahucios (Vives-Miró, González-Pérez \& Rullan, 2015). Por tanto, la otra cara de este modelo de crecimiento fundamentado en valores ficticios es las más de 600.000 ejecuciones hipotecarias (según datos del Consejo General del Poder Judicial). Todo ello, mientras se acumulan 800.000 viviendas nuevas sin vender (Oliver, 2013). 
En este contexto, Cataluña, conjuntamente con Andalucía y Valencia, es uno de los territorios con mayor volumen de ejecuciones hipotecarias realizadas durante el periodo 2008-2014 (Gutiérrez \& Domènech, 2017b; Méndez et al., 2014), con casi 100.000 ejecuciones hipotecarias. Este hecho delata que Cataluña ha sido también uno de los territorios que en la década 1998-2007 alcanzó mayores ratios de construcción de vivienda nueva, burbuja de precios y constitución de nuevas hipotecas. Se construyó un total de 657.550 viviendas y el precio de la vivienda se incrementó más de un 250\% en precios corrientes durante el periodo 1999-2006 (Gutiérrez \& Delclòs, 2015 y 2017). En este sentido, como apuntan Méndez y Plaza (2016), a mayor exposición a la burbuja, mayor intensidad de la crisis hipotecaria y los desahucios. La intensidad del modelo catalán hace que sea un ejemplo paradigmático para el estudio de la desposesión de vivienda. Además, como se podrá constatar en próximas secciones, este fenómeno se manifiesta a partir de unos contrastes territoriales internos, definidos precisamente por la desigual exposición a la deuda hipotecaria.

\section{Viviendas vacías, propiedad de las entidades financieras en Cataluña: apuntes metodológicos}

La paradójica situación explicada anteriormente en cuanto a la oleada de desahucios frente al crecimiento masivo de viviendas vacías llevó al Parlamento catalán, entre otras medidas, a promulgar un decreto ley con el fin de paliar este escenario. En marzo 2015, el parlamento de Cataluña aprobó el Decreto ley 1/2015, ${ }^{1}$ "de medidas extraordinarias y urgentes para la movilización del parque de viviendas provenientes de ejecución hipotecaria". ${ }^{2}$ Después del trámite parlamentario, en julio del mismo ańo fue aprobada la ley que regula el impuesto ${ }^{3}$ y en febrero de 2016 fue aprobado el reglamento ${ }^{4}$ que permite la aplicación efectiva del mismo. La política que se inicia mediante este Decreto representa una novedad en España, ya que es la primera comunidad que aprueba este tipo de Ley.

Según el texto del reglamento, las medidas aprobadas pretendían hacer frente a dos procesos relacionados con las viviendas acumuladas por la banca a través de ejecuciones hipotecarias que apuntaban problemáticas emergentes:

1 Diari Oficial de la Generalitat de Catalunya (DOGC) no 6839, de 26 de marzo de 2015.

2 El consejo de ministros en funciones aprobó el 22 de abril de 2016 la interposición de un recurso de inconstitucionalidad contra la Ley 14/2015 de impuesto a las viviendas vacías. Además, en el recurso incluía la petición de aplicación del artículo 161.1 de la Constitución, que supone la suspensión cautelar automática de cualquier ley autonómica objeto de recurso por la administración central, implicando que justo después del cobro de la primera anualidad de este impuesto, ha sido paralizado por parte del gobierno del Estado.

3 Ley 14/2015, del 21 de julio, del impuesto sobre las viviendas vacías, y de modificación de normas tributarias y de la Ley 3/2012. DogC no 6919, de 23 de julio de 2015.

4 Decreto 183/2016, de 16 de febrero, por el cual se aprueba el Reglamento del impuesto sobre las viviendas vacías. DOGC no 7061, de 18 de febrero de 2016. 
- La comercialización por parte de las entidades financieras de paquetes de títulos hipotecarios y viviendas que transmiten a fondos de inversión internacionales con descuentos muy importantes en el precio.

- El gran volumen de vivienda propiedad de las entidades financieras o de la SAREB $^{5}$ que no pueden movilizarse porque requieren obras de adecuación a las condiciones de habitabilidad vigente.

Por otra parte, según han detallado el Consejero de Territorio y Sostenibilidad y la Consejera de Gobernación, Administraciones Públicas y Vivienda de la Generalitat, el objetivo principal de la Ley no es solamente obtener una recaudación que permita la adquisición de nueva vivienda pública, sino especialmente incentivar, a través del recargo que supone no hacerlo, la salida al mercado de alquiler de estas viviendas vacías. ${ }^{6}$ En este sentido, las principales medidas que regula el decreto ley son, en primer lugar, el derecho de tanteo y retractación en favor de la Generalitat de Cataluña o de los entes locales de todas las viviendas provenientes de ejecuciones hipotecarias posteriores a abril de $2008 .^{7}$ En segundo lugar, la definición de dos medidas de carácter temporal (hasta 2021) para asegurar la rehabilitación de las viviendas en mal estado y de propiedad de las entidades financieras. ${ }^{8} \mathrm{Y}$, en tercer lugar, la creación de un registro administrativo de vivienda vacía en el que deben inscribirse las viviendas vacías u ocupadas sin título (ocupadas de forma alegal) propiedad de las entidades financieras (u otras personas jurídicas) adquiridas a través

5 La Sociedad de Gestión de Activos Procedentes de la Reestructuración Bancaria (sareB) fue creada en noviembre de 2012, fruto de los acuerdos del Memorandum of Understanding (Mou) firmado entre el Estado espańol y la Comisión Europea (Real Decreto Ley Estado a través del Fondo de Reestructuración Ordenada Bancaria, FROB) y en un 55\% por entidades privadas, esencialmente bancos. Conocida popularmente como "banco malo", pese a no ser una entidad financiera, ha sido una pieza clave del proceso de reestructuración y saneamiento de la banca espańola. Las entidades rescatadas con dinero público han transferido a la SAREB sus activos tóxicos provenientes del sector inmobiliario (valorados en más de 51.000 millones de euros) y esta ha recibido ayuda pública proveniente del rescate europeo a la banca espańola. Los compromisos firmados indican que en un plazo de quince años desde su constitución, la SAREB debe vender todos estos paquetes inmobiliarios. En caso contrario, el Estado deberá asumir las pérdidas económicas que de ello se deriven.

6 ara.cat (14/04/2016), "El Govern recapta 11,3 milions d'euros amb l'impost de pisos buits, 3 més que els que preveia" [http://www.ara.cat/societat/Govern-recapta-11-milions-impost-pisosbuits_0_1558644328.html]. Catalunya Plural (14/04/2016), "Els grans propietaris paguen a la Generalitat 11,3 milions d'euros d'impost sobre pisos buits”, por J. França [http://www.eldiario. es/catalunyaplural/Els-propietaris-Generalitat-milions-dimpost_0_505349966.html].

7 Se aplicará durante seis años, hasta el 2021, en los 72 municipios con alta demanda acreditada. Se priorizará la adquisición de viviendas situadas en zonas con un elevado riesgo de exclusión social y las viviendas adquiridas de personas físicas en los procesos de ejecución hipotecaria y mediante compensación o pago de la deuda con garantía hipotecaria (desahuciados).

8 Estas son: (i) Tipificación como una infracción grave en materia de calidad del parque inmobiliario (modificación artículo $124 \mathrm{f}$ de la Ley al derecho de la vivienda) la no ejecución de las obras de rehabilitación y adecuación necesarias para el cumplimiento de los requisitos que establece la normativa vigente de habitabilidad. (ii) Se incorpora un mecanismo de cesión temporal de las viviendas en el caso de que el titular (entidad financiera) no realice las obras de rehabilitación necesarias; se prevé una expropiación temporal del usufructo por parte de la Administración por un periodo de cuatro a diez ańos. 
de ejecución hipotecaria. A partir de este registro de viviendas vacías en manos de los bancos, el reglamento detalla que gravará las viviendas y a grandes propietarios de vivienda que estén vacías durante dos años o más en los 72 municipios identificados por la Agencia Catalana de la Vivienda como municipios con alta demanda de vivienda. ${ }^{9}$

En marzo de 2016 se inició el cobro del impuesto, el cual ha recaudado 11,3 millones de euros, que — según fuentes de la Consejería de Gobernación, Administraciones Públicas y Vivienda - se dedicarán a la adquisición de 260 viviendas vacías de los bancos de la bolsa proveniente de ejecuciones hipotecarias, ejerciendo el derecho de tanteo y retractación, con la finalidad de aumentar el parque público dedicado a alquiler social en los 72 municipios de acción prioritaria.

\section{Sobre el registro de viviendas vacías en propiedad de la banca de la Agencia Catalana de la Vivienda}

El registro de viviendas vacías en propiedad de la banca de la Agencia Catalana de la Vivienda ha constituido la base de datos de esta investigación, representando esta una innovación metodológica, ya que no se dispone de ninguna fuente directa o indirecta que aporte esta información en todo el Estado.

Dicho registro es exhaustivo, ya que es la base sobre la que se recaudó el impuesto en marzo de 2016. Este incluye para cada vivienda la información sobre su dirección postal, su sociedad propietaria, su estado de conservación (habitable o requiere rehabilitación) y su disponibilidad (vacía u ocupada).

A partir de una extracción de datos del registro, ${ }^{10}$ se han podido computar un total de 46.584 viviendas vacías propiedad de entidades financieras. Cabe apuntar que esta cifra no refleja el total de ejecuciones hipotecarias realizadas desde el inicio de la crisis en Cataluña, sino el total de viviendas que en marzo de 2016 acumulaban en su poder los bancos o sociedades vinculadas a estos. Es decir, todas aquellas que después de adquirirlas vía ejecución hipotecaria, hasta la fecha, los bancos no han podido vender (vía subastas, venta directa o a través de filias inmobiliarias a particulares o venta a fondos de inversión).

Aunque todas estas viviendas sean propiedad de los bancos o sociedades fruto de ejecuciones hipotecarias, pueden diferenciarse dos subcategorías según su origen. En primer lugar, aquellas que cuya ejecución hipotecaria ha comportado la pérdida de vivienda familiar (un desahucio). Y, en segundo lugar, las viviendas nuevas y sin primera ocupación que han acabado en propiedad de los bancos después de que estos ejecutasen la hipoteca de las empresas propietarias que las comercializaban (empresas constructoras y/o promotoras). Así, mientras la primera casuística se corresponde con familias desahuciadas, la segunda se refiere a los bloques de vivienda nueva vacía que proliferan en las periferias urbanas. Se trata, por tanto, de dos casuísticas muy diferentes que deben tratarse de forma desagregada.

9 Se trata de municipios que, a partir de estudios de demanda y mercado de la vivienda de la Agencia de la Vivienda de Cataluña (órgano dependiente de la Generalitat de Cataluña), se han considerado como zonas prioritarias para la política pública de vivienda. Son municipios con mayor demanda de vivienda y presión de precios.

10 Extracción realizada el 18 de marzo de 2016. 
El registro de la Agencia de Vivienda de Cataluña no discrimina las viviendas según estas dos tipologías. Por ello, los autores han definido un criterio para identificar y extraer las viviendas de la segunda tipología de la base. Se ha asumido que las direcciones postales que acumulan cuatro o más viviendas en manos del mismo banco se corresponden con vivienda nueva sin vender, ya que resulta altamente improbable que todos los desahucios de un bloque de viviendas los haya realizado el mismo banco. A partir de este criterio, del total de 46.584 viviendas del registro, se han identificado 37.310 obtenidas a través de ejecuciones hipotecarias que han conllevado un desahucio, mientras que las 9.274 restantes se corresponden con vivienda nueva sin vender que ha acabado en manos del banco que avalaba al constructor y/o promotor de la obra. El presente trabajo centra su análisis en las 37.310 viviendas en manos de los bancos fruto de un desahucio. Con el objetivo de dar respuesta a los interrogantes de investigación, los datos han sido explotados en dos tipos de agregación: una según la titularidad de las viviendas (bancos y sociedades propietarias) y otra según su distribución territorial (municipal e inframunicipal). La primera aproximación ha permitido constatar que entidades financieras han acumulado más viviendas a través de ejecuciones hipotecarias, mientras que la segunda ha permitido analizar los contrastes territoriales en el desarrollo de la crisis hipotecaria en Cataluña.

Una forma de valorar la gran magnitud de las cifras analizadas es contraponerla con el volumen de vivienda pública en Cataluña. Un estudio reciente cuantifica en menos de 30.000 unidades el total de parque de vivienda pública dedicada a alquiler social (Bermúdez \& Trilla, 2014). Este dato incluye 14.000 viviendas titularidad de la Agencia de la Vivienda de Cataluńa, 11.000 del Patronato Municipal de la Vivienda de Barcelona y 3.000 del resto de patronatos municipales. Se trata de menos del 1\% del parque de vivienda de Cataluña. A estas cabe añadir otras 30.000 viviendas que cuentan con un alquiler social gracias a ayudas públicas (19.000 ayudas al alquiler, 9.000 viviendas alquiladas a través de servicios municipales de mediación y 1.200 de la Red de Viviendas de Inclusión de Cataluña) (Bermúdez \& Trilla, 2014, pp. 4-5). Es decir, los bancos y sociedades inmobiliarias vinculadas a estos acumulan más vivienda que la suma de todo el parque público de Cataluña. Esto es, 46.584 viviendas (37.310 provenientes de desahucios) contra 30.000.

\section{Los bancos como nuevos grandes propietarios de vivienda}

La gestión de la crisis y las políticas implantadas en España desde que estalló la burbuja inmobiliaria estuvieron dirigidas a mantener el mismo modelo de acumulación que había gestado su agotamiento. En este contexto, una de las principales estrategias desplegadas para alcanzar este objetivo ha sido el rescate bancario (Vives-Miró \& Rullan, 2014). Para ello, entre 2008 y 2009, se crearon los instrumentos que se encargarían de su gestión: el Fondo de Adquisición de Activos Financieros (FAAF) ${ }^{11}$

11 El faAf fue creado en octubre de 2008 a través de un real decreto RD-ley 6/2008 del 10 de octubre 2008, dotado con efectivo proveniente de los presupuestos generales del Estado. 
y el Fondo de Reestructuración Ordenada Bancaria (FROB) ${ }^{12}$. El rescate bancario se desarrolló a través de dos líneas de actuación. La primera consistió en el saneamiento mediante la creación de la SAREB y la transferencia de los activos tóxicos, bien a la SAREB, o bien hacia fondos de inversión mediante la venta de sus carteras inmobiliarias (Gutiérrez \& Domènech, 2017b). Y la segunda línea de actuación, llevada a cabo en paralelo al saneamiento, fue la reestructuración bancaria o bancarización de las cajas de ahorros. Esta se desarrolló mediante la fusión de diferentes entidades financieras a cambio de fondos públicos o mediante la nacionalización de entidades. Como resultado de este proceso, de las 45 cajas existentes en 2009, quedan 11 entidades y dos pequeńas cajas de ahorro locales. El volumen total de dinero público que directa e indirectamente se ha inyectado a la banca asciende a 1,4 billones de euros, contando las ayudas directa e indirectas (Plataforma Auditoría Ciudadana de la Deuda, 2013), aunque según los datos del Banco de España solo ha recibido un total de 61.000 millones de euros. ${ }^{13}$ En otras palabras, esta estrategia implica una enorme subvención pública al sector bancario, la socialización de las pérdidas de los negocios inmobiliarios de las cajas de ahorro y la conversión de la deuda privada en deuda pública.

A partir de esta situación, la lógica de apropiación de rentas por parte de la banca se ha traducido en que, a través de ejecuciones hipotecarias, los distintos bancos se han convertido en grandes propietarios de viviendas, las que permanecen vacías a la espera de una mayor rentabilidad. Se trata de la estrategia de la producción de las rent gaps. La rent gap ha sido explicada como "la diferencia entre el nivel de la renta potencial del suelo y la renta actual capitalizada bajo el actual uso del suelo" (Smith, 2012, p. 126). En este sentido, la degradación de algunos barrios o áreas urbanas - como en el caso que nos ocupa - a través de su abandono puede provocar que se alcancen altos niveles de diferencia potencial de renta (Smith, 2012). En otras palabras, la concentración de viviendas vacías procedentes de dichas ejecuciones hipotecarias puede generar un sostenido descenso de precios que, al alcanzar un determinado nivel, permitirá una posible reinversión rentable. Esta es la que puede entenderse como la fase cero de un proceso de gentrificación (Smith, 2012).

En Cataluña, según los datos del registro de viviendas vacías, un total de 30.243 viviendas actualmente están en manos de entidades financieras y han sido adquiridas a través de ejecuciones hipotecarias desembocadas en desahucios. De estas, 26.938 pertenecen directamente a los bancos (el 55\%), 7.927 a filiales inmobiliarias de bancos (el 21\%) y 1.667 a fondos de titulización (el 5\%) (figura 1). Otras 6.290 viviendas que han seguido el mismo proceso están ahora en manos de la SAREB, el $17 \%$ del total. Estas están a la espera de ser compradas nuevamente por entidades financieras o por fondos buitres (como se ha llevado a cabo con las viviendas que ha vendido la SAREB hasta este momento). Las 778 viviendas restantes (el 2\%) son propiedad de otro tipo de sociedades.

12 El frob fue creado en junio de 2009 con el objetivo de promover la reestructuración de entidades y las fusiones voluntarias y la bancarización de cajas. Es el instrumento que vehicula la inyección de capital público.

13 Banco de España (2014-06-12). "Nota Informativa sobre ayudas públicas en el proceso de reestructuración del sistema bancario español (2009-2013)”. http://bit.ly/2x6EPCK 
FIGURA I | Viviendas vacías según tipo de propietario

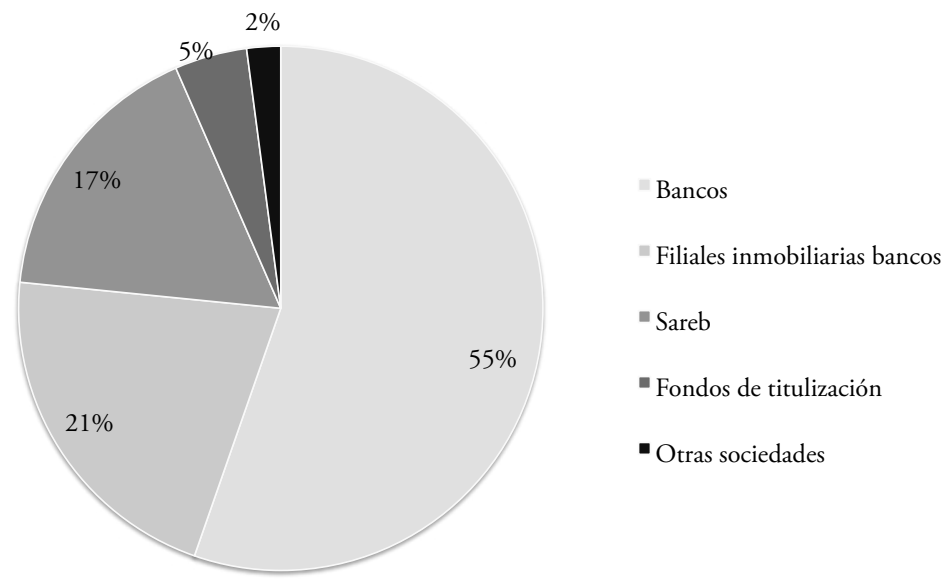

FUENTE ELABORACión PROPIA A PARTIR DE DATOS DEL REgISTRO DE VIVIENDA VACía DE LA GENERALitat de CATAluña (DATOS DE MARZo DE 2OI6)

La tabla 1 permite detallar la distribución de estas viviendas por bancos o filial inmobiliaria asociada. Entre las filiales inmobiliarias vinculadas a los bancos destacan las diferentes sociedades de Caixabanc (la primera entidad financiera de Cataluña). En este caso, se puede constatar que el banco ha traspasado todos sus activos inmobiliarios a estas sociedades, para así sanear sus cuentas. La multiplicidad de sociedades vinculadas al ввvA se explica a partir de las filiales inmobiliarias de las diferentes cajas que integraron Unnim (Caixa de Manlleu, Caixa de Terrassa y Caixa de Sabadell), adquirida posteriormente por el Bвva. No obstante, para realizar un análisis global de las propiedades inmobiliarias que posee cada banco, es necesario agregar a las viviendas de cada uno de ellos, las que están en propiedad de sus filiales inmobiliarias. Por ello, en la figura 2 se representan de forma agregada las cifras de los bancos y sus respectivas filiales inmobiliarias. Los tres bancos con más viviendas acumuladas son el BвvA (13.443 viviendas), Bankia (5.747 viviendas) y Caixabank (3.712 viviendas). Las viviendas del BвVA son computadas a partir de las que posee el propio banco (6.598); las que acumula Catalunya Banc, adquiridas por el вBVA (1.877, más 1.068 de Gescat); y las de unNim Sociedad Gestión Activos Inmobiliarios (1.629), Arrahina (224), Anida (214) y Arrels ст (99). En las viviendas de Bankia están integradas las propias del banco (5.678), y las de Haya Real Estate (69). Por su parte, Caixabank cuenta con 292 viviendas, más las de Buildingcenter (2.423), Criteria Caixaholding (978) y las de Servihabitat (19). En total, las tres entidades acumulan 21.168 viviendas, un $74 \%$ del total de las que poseen los bancos. En este sentido, estamos ante un claro proceso de concentración de la propiedad, cuyos protagonistas representan una novedad en relación con la distribución histórica de la propiedad de vivienda en Cataluña. 
TABLA I | Número de viviendas vacías por propietarios

\begin{tabular}{|c|c|c|c|}
\hline TOTAL BANCOS & 26.938 & $\begin{array}{c}\text { TOTAL FILIALES INMOBILIARIAS } \\
\text { BANCOS }\end{array}$ & 7.927 \\
\hline BBVA & 6.598 & Buildingcenter (Caixabanc) & 2.423 \\
\hline Bankia & 5.678 & $\begin{array}{l}\text { UNNIM Sociedad Gestión Activos } \\
\text { Inmobiliarios (BBVA) }\end{array}$ & 1.629 \\
\hline Catalunya Banc & 1.877 & Gescat (Catalunya Banc) & 1.068 \\
\hline Banco Santander & 1.842 & Criteria Caixaholding (CaixaBanc) & 978 \\
\hline Banco Popular & 1.367 & Aliseda (Banco Popular) & 367 \\
\hline Banco Mare Nostrum & 1.211 & Abanca Inmobiliario (Abanca) & 351 \\
\hline Banc Sabadell & 656 & Arrahona (BBVA) & 224 \\
\hline UCI financera & 466 & Anida (BBVA) & 214 \\
\hline Cajas Rurales Unidas S. Coop. Crédito & 366 & Solvia (Banc Sabadell) & 194 \\
\hline Caixabank & 292 & Altamira (Banco Santander) & 115 \\
\hline CreditAgricole & 205 & Arrels CT (BBVA) & 99 \\
\hline Kutxabank & 69 & Cimentados2 (CajaMar) & 90 \\
\hline Abanca & 18 & Daenpa (Abanca) & 84 \\
\hline Targobank & 2 & Haya Real Estate (Bankia) & 69 \\
\hline \multirow[t]{2}{*}{ Caja de Arquitectos S. Coop. Crédito } & 1 & Servihabitat (CaixaBanc) & 19 \\
\hline & & Inmobiliaria Caixa Geral & 3 \\
\hline \multirow[t]{2}{*}{ Total fondos de titulización } & 1.667 & & \\
\hline & & SAREB & 6.290 \\
\hline Total otras sociedades & 778 & & \\
\hline TOTAL & & & 37.310 \\
\hline
\end{tabular}

FUENTE ELABORACión PROPIA A PARTiR DE DATOS DEL REgistro DE VIVIENDA VACía de LA GENERALitAT DE CATALUŃA (DATOS DE MARZO DE 20I6)

FIGURA 2 | Distribución de las viviendas vacías según entidad financiera propietaria

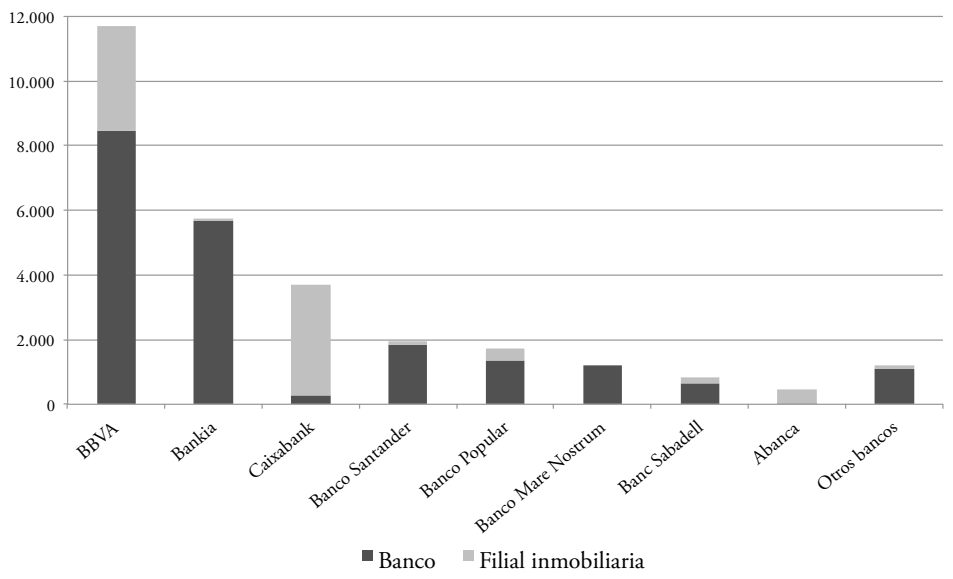

NOTA LAS VIVIENDAS DE CATALUNYA BANC, PRESENTADAS DE FORMA DESAGREGADA EN LA TABLA I, SE SUMAN A LAS DEL BBVA, YA QUE FUERON ABSORBIDAS POR ESTE EN SEPTIEMBRE DE 20 I 6.

FUENTE ELABORACIÓN PROPIA A PARTIR DE DATOS DEL REGISTRO DE VIVIENDA VACÍA DE LA GENERALitAT de CATALUŃa (DATOS DE MARZO DE 2OI6) 
No obstante, más allá de la acumulación de viviendas en pocas entidades, otra característica relevante que se puede extraer de los datos es la concentración en aquellas rescatadas con dinero público. La tabla 2 relaciona las viviendas que tiene cada banco con el capital público (en millones de euros) que han recibido. Con el fin de tener una visión más contrastada, se presentan dos cifras relativas a los fondos públicos: las oficiales y las presentadas por la Plataforma Auditoría Ciudadana de la Deuda. ${ }^{14}$

TABLA 2 Relación entre propietarios de viviendas y fondos públicos adquiridos

\begin{tabular}{|c|c|c|c|c|c|c|}
\hline & VIVIENDAS & $\%$ & $\begin{array}{c}\text { DATOS } \\
\text { OFICIALES } \\
(\mathrm{M} €)\end{array}$ & $\%$ & $\begin{array}{c}\text { PLATAFORMA } \\
\text { DE LA DEUDA } \\
(M €)\end{array}$ & $\%$ \\
\hline BBVA & 13.443 & 44 & $13.005(1)$ & 21 & $17.309(1)$ & 17 \\
\hline Bankia & 5.747 & 19 & 22.424 & 36 & 36.183 & 36 \\
\hline CaixaBanc & 3712 & 12 & $6.475(2)$ & 11 & $8.200(2)$ & 8 \\
\hline Banco Santander & 1.957 & 6 & & 0 & & 0 \\
\hline Banco Popular & 1.734 & 6 & & 0 & & 0 \\
\hline Banco Mare Nostrum & 1.211 & 4 & 1.890 & 3 & 4.612 & 5 \\
\hline Banc Sabadell & 850 & 3 & $5.249(3)$ & 9 & $13.222(3)$ & 13 \\
\hline UCI financera & 466 & 2 & & 0 & & 0 \\
\hline Cajas Rurales Unidas & 456 & 2 & & 0 & & 0 \\
\hline Abanc & 453 & 1 & 9.052 & 15 & 10.281 & 10 \\
\hline CreditAgricole & 205 & 1 & & 0 & & 0 \\
\hline Otros bancos (4) & 75 & 0 & & 0 & & 0 \\
\hline Caja 3 & & & 407 & 1 & 1.097 & 1 \\
\hline Unicaja & & & 1.129 & 2 & 1.846 & 2 \\
\hline Liberbank & & & 1.864 & 3 & 6.974 & 7 \\
\hline Cajasur & & & & 0 & 358 & 0 \\
\hline TOTAL & 30.309 & 100 & 61.495 & 100 & 100.082 & 100 \\
\hline
\end{tabular}

NOTAS (I) AYUDAS A CATALUNYA BANC, ADQUIRIDO POR BBVA. (2) AYUDAS A BANCO DE VALENCIA Y A GRUPO BANCA CÍVICA, ADQUIRIDOS POR CAIXA BANC. (3) AYUDAS A LA CAM, ADQUIRIDA POR EL BANCO DE SABADELL. (4) INCLUYE LAS ENTIDADES FINANCIERAS CON MENOR VOLUMEN DE VIVIENDA EN PROPIEDAD Y SIN AYUDA PÚBLICA (KUTXABANK, CGD, TARGONANK Y CAJA DE ARQUITECTOS).

FUENTE ELABORACión PROPIA A PARTIR DE DATOS DEL REGISTRO DE VIVIENDA VACía DE LA GENERALITAT DE CATALUÑA (DATOS DE MARZO DE 2OI 6); PLATAFORMA AUDITORÍA CIUDADANA DE LA DEUDA, 2OI3; SÁNCHEZ MATO, 2OI3; Y BANCO DE ESPAÑa (2OI4-O6-I 2)

14 La Plataforma Auditoría Ciudadana de la Deuda (PACD) es una plataforma ciudadana creada en octubre de 2011 por miembros que participaron en el I 5M, ¿Quién debe a quién?, Attac, Democracia Real Ya, Economistas sin Fronteras y otros grupos y personas a título individual. Forma parte de la Red Internacional de Auditorías Ciudadanas de la deuda (International Citizen Audit Network - ICAN). A través de mociones ciudadanas presentadas por la PACD, se ha declarado ilegítima parte de la deuda pública de algunos municipios. Han creado la herramienta Observatorio Ciudadano Municipal para exportar el modelo a todos los municipios de Espańa. Han publicado diferentes informes sobre la deuda espańola, los rescates bancarios y los presupuestos públicos. 
En este sentido, según los datos oficiales, los dos bancos que han recibido más fondos públicos son Bankia (22.424 millones de euros) y BBVA (13.005 millones de euros). También lo son según la Auditoría de la Deuda, aunque con diferentes cifras: 36.183 millones para el Bankia y 17.309 para el BBVA, apropiándose del 57\% o del $63 \%$ del total del dinero público dedicado a la "reestructuración bancaria". Estos dos bancos, a la vez, tienen 19.190 viviendas vacías, un 63\% del total. De esta manera, se constata que las entidades con más viviendas en propiedad provenientes de ejecuciones hipotecarias son, también, aquellas que más fondos públicos han recibido en un contexto de austeridad y recortes sociales.

\section{Distribución espacial de la vivienda en manos de la banca}

La representación de la distribución espacial de las viviendas propiedad de las entidades financieras y adquiridas a través de ejecuciones hipotecarias que han derivado en desahucios, si es expresada en valores absolutos, tiende a reflejar el ranking urbano. Es decir, los bancos acumulan más vivienda en las principales ciudades catalanas. Esta situación se evidencia en la figura 3, la cual presenta la distribución del total de viviendas en manos de las entidades financieras por municipio. Así, destaca Barcelona, su entorno metropolitano, el litoral y las capitales provinciales (Lleida, Tarragona y Girona). Sin embargo, ya en esta figura se pueden apreciar valores significativamente elevados en otras ciudades del interior de Cataluña, como Reus, Tortosa, Manresa, Figueres, Vic, Amposta o Balaguer, apuntando un primer signo del desarrollo geográfico desigual de la desposesión de vivienda en Cataluńa.

FIGURA 3 Viviendas en manos de las entidades financieras provenientes de desahucios (total por municipio)

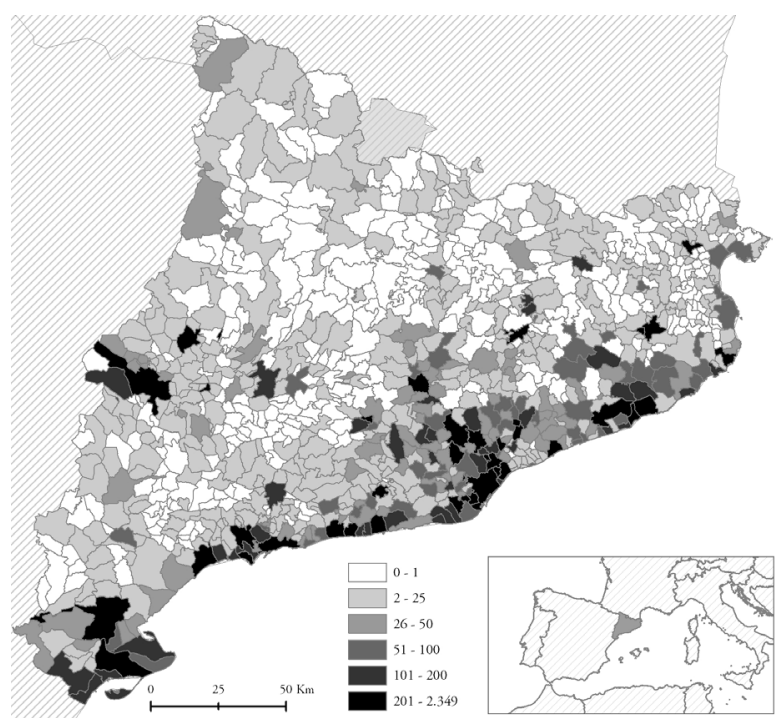

FUENTE ELABORACIÓN PROPIA A PARTIR DE DATOS DEL REGISTRO DE VIVIENDA VACÍA DE LA GENERALiTAT DE CATALUŃA (DATOS DE MARZO DE 2OI6) 
Para mayor detalle, la tabla 3 presenta los 30 municipios en los que las entidades financieras acumulan más viviendas. Los rankings de volumen de población y de vivienda en manos de la banca se asemejan en las nueve primeras ciudades de Cataluña. A partir de ahí, se aprecian diferencias significativas entre ambos rankings. Esto permite identificar municipios especialmente afectados por los desahucios derivados de ejecuciones hipotecarias - aquellos que alcanzan valores claramente superiores al que le correspondería según su ranking urbano-. Entre estos destacan Salt (Girona), Tortosa y Amposta (Tierras del Ebro), El Vendrell y Calafell (litoral de Tarragona), Mollerussa y Balaguer (Lleida). En estos casos, el ratio de viviendas en manos de los bancos por 1.000 habitantes supera las 20, alcanzando las 67 en el caso de Salt, mientras que el ratio medio en Cataluña es de 9,6. Los siete municipios mencionados presentan indicadores socioeconómicos que denotan una precarización superior a la media catalana (mayor tasa de paro, menor renta familiar y mayor concentración de población extranjera). Esto apunta a que los territorios donde los procesos de desposesión de vivienda se han desarrollado con mayor intensidad han sido aquellos más vulnerables.

TABLA 3 Municipios con mayor volumen de vivienda propiedad de entidades financieras

\begin{tabular}{|c|c|c|c|c|}
\hline MUNICIPIO & VIVIENDAS (I) & $\begin{array}{c}\text { RANKING } \\
\text { VIVIENDAS }\end{array}$ & $\begin{array}{l}\text { RANKING } \\
\text { POBLACIÓN }\end{array}$ & $\begin{array}{c}\text { RATIO } \\
\text { VIVIENDAS (2) }\end{array}$ \\
\hline Barcelona & 2.349 & 1 & 1 & 2,9 \\
\hline Terrassa & 1.727 & 2 & 4 & 17,0 \\
\hline L'Hospitalet de Llobregat & 1.657 & 3 & 2 & 14,8 \\
\hline Sabadell & 1.365 & 4 & 5 & 14,6 \\
\hline Badalona & 1.305 & 5 & 3 & 14,1 \\
\hline Lleida & 1.212 & 6 & 6 & 18,2 \\
\hline Tarragona & 1.094 & 7 & 7 & 16,6 \\
\hline Reus & 955 & 8 & 10 & 19,2 \\
\hline Sta. Coloma de Gramenet & 929 & 9 & 9 & 19,1 \\
\hline Salt & 758 & 10 & 43 & 67,5 \\
\hline Manresa & 585 & 11 & 15 & 14,8 \\
\hline Mataró & 539 & 12 & 8 & 9,9 \\
\hline Rubí & 536 & 13 & 16 & 16,2 \\
\hline Girona & 521 & 14 & 11 & 11,0 \\
\hline Tortosa & 443 & 15 & 38 & 26,1 \\
\hline El Vendrell & 394 & 16 & 34 & 12,7 \\
\hline Amposta & 385 & 17 & 62 & 35,4 \\
\hline Figueres & 325 & 18 & 26 & 15,5 \\
\hline Granollers & 301 & 19 & 21 & 11,5 \\
\hline Vilanova i la Geltrú & 269 & 20 & 17 & 8,2 \\
\hline Calafell & 264 & 21 & 54 & 9,8 \\
\hline Mollet del Vallès & 257 & 22 & 23 & 11,5 \\
\hline Mollerussa & 251 & 23 & 87 & 38,2 \\
\hline
\end{tabular}


(continuación)

\begin{tabular}{|l|c|c|c|c|}
\hline \multicolumn{1}{|c|}{ MUNICIPIO } & VIVIENDAS (I) & $\begin{array}{c}\text { RANKING } \\
\text { VIVIENDAS }\end{array}$ & $\begin{array}{c}\text { RANKING } \\
\text { POBLACIÓN }\end{array}$ & $\begin{array}{c}\text { RATIO } \\
\text { VIVIENDAS (2) }\end{array}$ \\
\hline Vic & 245 & 24 & 28 & 12,8 \\
\hline Balaguer & 245 & 25 & 77 & 29,7 \\
\hline Vilafranca del Penedès & 240 & 26 & 29 & 12,6 \\
\hline Sant Boi de Llobregat & 238 & 27 & 14 & 6,9 \\
\hline Cornellà de Llobregat & 237 & 28 & 13 & 6,5 \\
\hline Canovelles & 226 & 29 & 82 & 35,6 \\
\hline Palafrugell & 224 & 30 & 58 & 13,1 \\
\hline
\end{tabular}

NOTAS (I) TOTAL DE VIVIENDAS PROPIEDAD DE LAS ENTIDADES FINANCIERAS PROVENIENTE DE DESAHUCIOS POR MUNICIPIO.

(2) RATIO DE VIVIENDAS PROPIEDAD DE LAS ENTIDADES FINANCIERAS PROVENIENTE DE DESAHUCIOS POR MUNICIPIO POR CADA I.OOO VIVIENDAS.

FUENTE ELABORACIÓN PROPIA A PARTIR DE DATOS DEL REGISTRO DE VIVIENDA VACÍA DE LA GENERALiTAT de CATAluña (MARZO DE 2OI6) Y DEL CENSO DE POBLACión Y VIVIENDAS DE 2O I I (INSTITUTO NACIONAL DE ESTADÍSTICA)

La tabla 4 permite evidenciar los vínculos entre precariedad y concentración de procesos de desposesión de vivienda. Incluye los 20 municipios que alcanzan una ratio más elevada de viviendas propiedad de los bancos por cada 1.000 viviendas del propio municipio. Se puede constatar cómo todos ellos tienen una Renta Familiar Disponible Bruta (datos de 2013) claramente inferior a la media catalana. Para verificar la correlación estadística entre ambas variables, se ha realizado el cálculo de correlación estadística de Pearson ${ }^{15}$ entre los valores de renta familiar disponible bruta por habitante por municipio y la ratio de viviendas propiedad de la banca por 1.000 viviendas por los 946 municipios de Cataluña. El resultado muestra una correlación negativa de un 0,71 . Es decir, denota cómo, a menor renta, mayor número de viviendas propiedad de la banca, todo ello con una correlación relativamente intensa.

TABLA 4 Municipios con mayor volumen de vivienda propiedad de entidades financieras

\begin{tabular}{|c|l|l|c|c|c|c|}
\hline RANKING & MUNICIPIO & PROVINCIA & RFDB (I) & POBLACIÓN (2) & VIVIENDAS (3) & RATIO (4) \\
\hline 1 & Salt & Girona & 73,9 & 29.342 & 758 & 67,5 \\
\hline 2 & Constantí & Tarragona & 78,4 & 6.416 & 114 & 42,6 \\
\hline 3 & Mollerussa & Lleida & 80,9 & 14.900 & 251 & 38,2 \\
\hline 4 & Alcarràs & Lleida & 84,3 & 9.372 & 159 & 36,7 \\
\hline 5 & Canovelles & Barcelona & 87,5 & 15.906 & 226 & 35,6 \\
\hline 6 & Amposta & Tarragona & 70,9 & 20.952 & 385 & 35,4 \\
\hline 7 & Vidreres & Girona & 88,7 & 7.741 & 128 & 33,6 \\
\hline 8 & Ulldecona & Tarragona & 62 & 6.637 & 124 & 31,2 \\
\hline
\end{tabular}

15 El coeficiente de correlación de Pearson es una medida de relación lineal entre dos variables aleatorias. Arroja resultados entre $-1,0$ y 1 , siendo 1 una correlación absoluta positiva, 0 una ausencia de correlación total y -1 una correlación negativa o inversa absoluta. 
(continuación)

\begin{tabular}{|c|l|l|c|c|c|c|}
\hline RANKING & MUNICIPIO & PROVINCIA & RFDB (I) & POBLACIÓN (2) & VIVIENDAS (3) & RATIO (4) \\
\hline 9 & $\begin{array}{l}\text { Maçanet de la } \\
\text { Selva }\end{array}$ & Girona & 83,5 & 6.887 & 115 & 29,8 \\
\hline 10 & Balaguer & Lleida & 77,3 & 16.479 & 245 & 29,7 \\
\hline 11 & Tortosa & Tarragona & 80,9 & 33.864 & 443 & 26,1 \\
\hline 12 & Deltebre & Tarragona & 67,6 & 11.676 & 159 & 25,4 \\
\hline 13 & Anglès & Girona & 88,8 & 5.540 & 63 & 25,0 \\
\hline 14 & Tordera & Barcelona & 86 & 16.433 & 211 & 24,9 \\
\hline 15 & Sils & Girona & 92,5 & 5.797 & 65 & 24,7 \\
\hline 16 & $\begin{array}{l}\text { Sta. Margarida } \\
\text { de Montbui }\end{array}$ & Barcelona & 72,8 & 9.648 & 109 & 24,5 \\
\hline 17 & $\begin{array}{l}\text { St. Vicenç de } \\
\text { Castellet }\end{array}$ & Barcelona & 88,1 & 9.246 & 115 & 24,5 \\
\hline 18 & L'Arboç & Tarragona & 84,2 & 5.513 & 58 & 23,6 \\
\hline 19 & Roda de Ter & Barcelona & 91,6 & 6.122 & 55 & 21,4 \\
\hline 20 & $\begin{array}{l}\text { Sta. Coloma de } \\
\text { Farners }\end{array}$ & Girona & 85,8 & 12.681 & 124 & 21,3 \\
\hline
\end{tabular}

NOTAS: (I) RENTA FAMILIAR DiSPONible BRUTA, 2013 (BASE 20IO). DATOS RELATivos a LA MEdia CATAluña (ÍNDice CATAluña=ioo). (2) habitantes 20I5. (3) total de Viviendas PROPIEDAD DE LAS ENTIDADES FINANCIERAS PROVENIENTE DE DESAHUCIOS POR MUNICIPIO. (4) RATIO DE VIVIENDAS PROPIEDAD DE LAS ENTIDADES FINANCIERAS PROVENIENTE DE DESAHUCIOS POR MUNICIPIO POR CADA I.OOO VIVIENDAS.

FUENTE: ELABORACIÓN PROPIA A PARTIR DE DATOS DEL REGISTRO DE VIVIENDA VACÍA DE LA

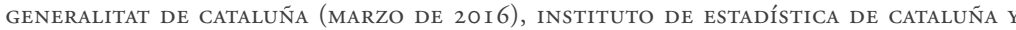
PADRóN MUNICIPAL DE HABITANTES (20I5)

La figura 4 presenta una lectura espacial de esta ratio por municipio. Permite matizar el anterior mapa (figura 3) y muestra unas pautas territoriales claras. Se trata de la geografía de la deuda hipotecaria impagada. Por ello, en primer lugar, reproduce aquellos territorios más afectados por el tsunami urbanizador (Gutiérrez \& Delclòs, 2015 y 2017). Estas son las áreas de expansión de la región metropolitana de Barcelona hacia el interior de Cataluña, pero también en sentido norte y sur en el litoral. Se refleja también su efecto sobre ciudades pequeńas y medias del interior (capitales comarcales, como Figueres, Igualada, Manresa, Tàrrega, Valls y otras ya citadas, como Balaguer o Mollerussa), pero también municipios de su entorno inmediato. En este sentido, destaca especialmente la corona de la ciudad de Lleida. Sin embargo, la afectación más intensa se manifiesta en los municipios meridionales (Amposta, Deltebre, Sant Carles de la Ràpita, Tortosa y Ulldecona). En este caso, se reproduce la confluencia entre un territorio especialmente afectado por la crisis y la destrucción de empleo, y que, a su vez, experimentó un gran crecimiento del sector de la construcción durante el boom inmobiliario. Se trata de un territorio con una industria y sector agrícola en retroceso que vio el crecimiento rápido de la construcción y el potencial turístico del Delta del Ebro como un refugio de inversión rentable y generación de rentas. Como apunta Burriel (2014), el mapa de la crisis económica en España es el negativo del mapa de la burbuja inmobiliaria. A mayor exposición al ladrillo, mayor caída a partir del inicio de la crisis. La proliferación de los desahucios por ejecución hipotecaria refleja también esta dinámica. 
FIGURA 4 Viviendas en manos de las entidades financieras provenientes de desahucios (ratio por 1.000 viviendas y municipio)

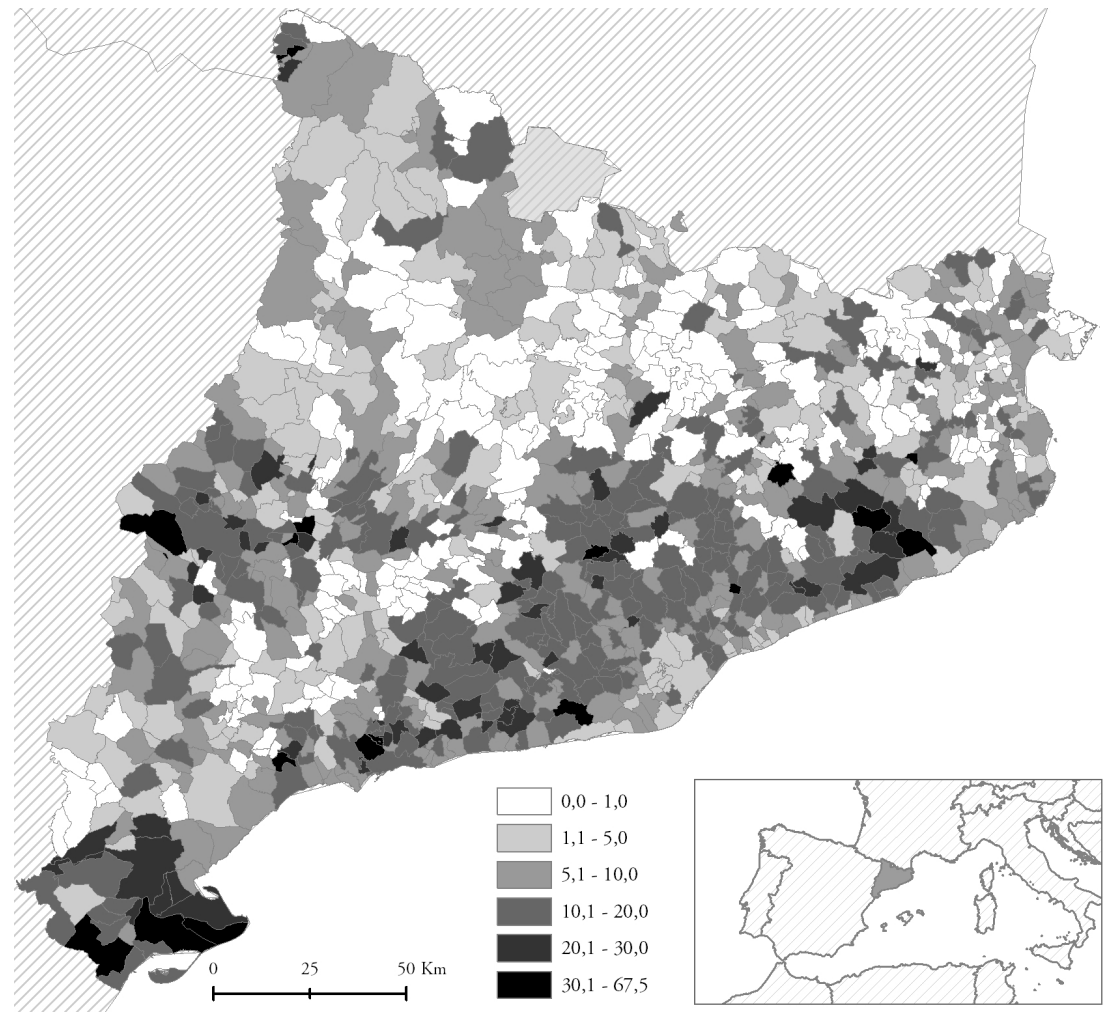

FUENTE ELABORACIÓN PROPIA A PARTIR DE DATOS DEL REGISTRO DE VIVIENDA VACÍA DE LA GENERALITAT DE CATALUÑA (DATOS DE MARZO DE 2OI6)

Este desarrollo geográfico desigual de la crisis hipotecaria se reproduce a todas las escalas, manifestándose también los contrastes y la desigualdad entre los barrios de las ciudades (Gutiérrez \& Domènech, 2017a). Para ilustrar este fenómeno, la figura 5 muestra la distribución de viviendas propiedad de los bancos en la ciudad de Barcelona. El mapa representa la distribución espacial de esta vivienda y los valores relativos (ratios por cada 1.000 viviendas) en los 73 barrios de la ciudad. La situación es clara: los barrios más precarizados son los que presentan más procesos de desposesión de vivienda. Se encuentran especialmente en los barrios del norte, caracterizados por su origen obrero y con concentración de vivienda social. Destaca el elevado volumen de vivienda en manos de los bancos en algunos de los barrios del distrito de Nou Barris, tales como, la Trinitat Nova, Torre Baró o Ciutat Meridiana; pero también en otros barrios del norte, como la Trinitat Vella, el Bon Pastor el Carmel, el Turó de la Peira, les Roquetes, y el Besòs i el Maresme, así como el barrio del Raval en el centro histórico. Por su parte, los barrios burgueses en los distritos de Sarrià-Sant Gervasi, les Corts y l'Eixample (especialmente l'Eixample Esquerra) 
son las zonas con menor presencia de vivienda en manos de los bancos. De hecho, en este caso la correlación estadística de Pearson entre renta familiar disponle bruta y el ratio de vivienda en manos de los bancos por cada 1.000 viviendas arroja unos resultados todavía más intensos: una correlación negativa de $-0,81$.

Figura 5 Viviendas en manos de las entidades financieras provenientes de desahucios en Barcelona

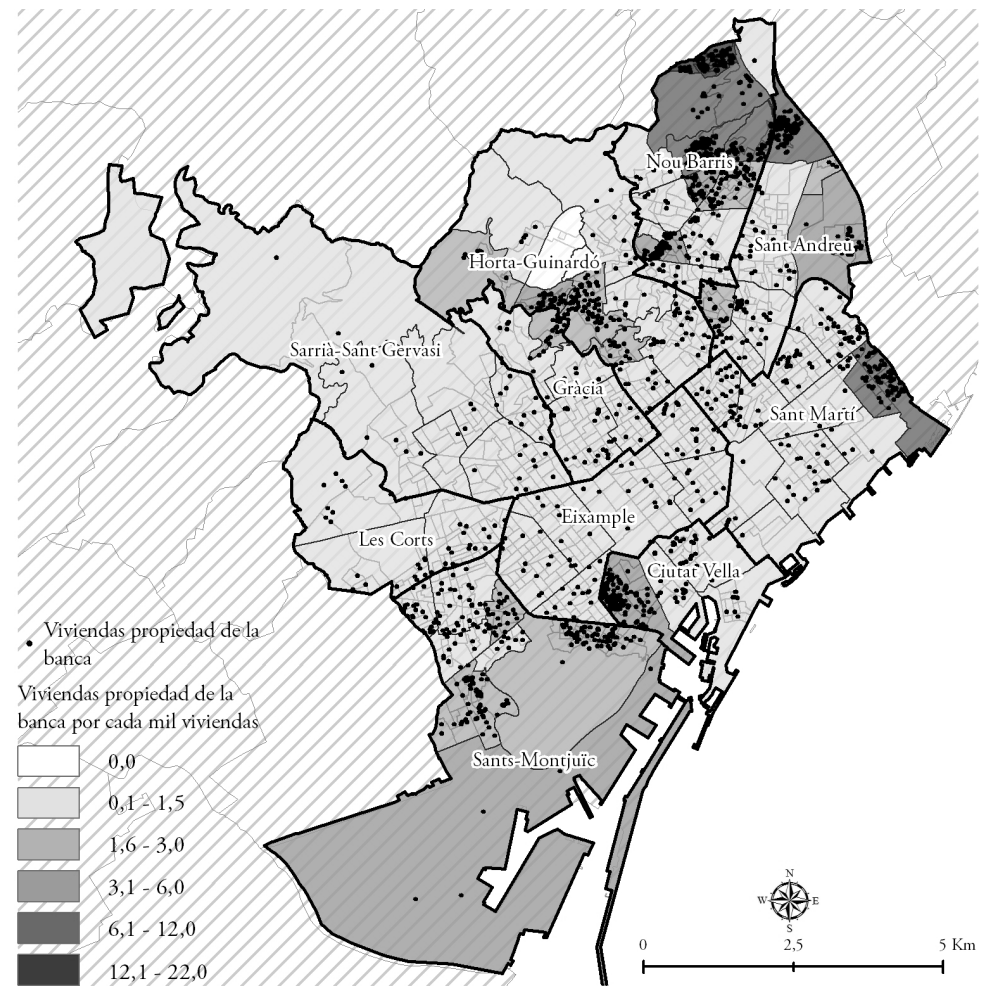

FUENTE ELABORACión PROPIA A PARTIR DE DATOS DEL REgISTRO DE VIVIENDA VACía de LA GENERALitAT DE CATALUÑa (DATOS DE MARZo DE 20I6)

\section{Conclusiones}

El desarrollo del rescate bancario, tanto en la forma de saneamiento de las cajas de ahorros como en la de fusión de las cajas y conversión en bancos, ha devenido en Cataluña, seguramente al igual que en España, un claro proceso de intensificación de la lógica de acumulación de rentas urbanas por desposesión de vivienda. Se trata de una estrategia financiera implementada con el pretexto de la crisis, que tiene por finalidad una nueva movilización de los capitales que no encontraban su espacio para ser rentables desde que estalló la burbuja.

Que las cajas de ahorro hayan sido rescatadas con fondos públicos se traduce en la socialización de sus pérdidas en los negocios inmobiliarios. No obstante, este 
no es el único beneficio que las entidades financieras han obtenido de la crisis, ya que gran parte de su negocio en esas circunstancias se ha realizado a través de las ejecuciones hipotecarias, mediante las cuales han acumulado un importante stock de vivienda: asciende a 37.310 unidades provenientes directamente de desahucios. Por tanto, se puede afirmar que la reestructuración del régimen de acumulación espańol implantada desde 2008 está implicando transformaciones en la propiedad de la vivienda, aumentando considerablemente la propiedad de entidades financieras, fondos de titulización y fondos buitres a través del traspaso de propiedad de estas viviendas, desde las familias a las entidades financieras. En otras palabras, la banca ha podido reorganizar sus estrategias de acumulación por medio de la desposesión de vivienda de muchas familias, el trasvase de la deuda bancaria al sector público, las subvenciones directas y los fondos públicos. De hecho, las entidades financieras rescatadas con dinero público son las que concentran más viviendas que provienen de desahucios. Con esta lógica, dichas entidades financieras han emergido como nuevos grandes propietarios de vivienda en Cataluña. Este fenómeno es de tal magnitud, que los bancos poseen actualmente más viviendas que la suma de todo el parque de titularidad pública dedicada a alquiler asequible, lo que permite proyectar su papel clave en el siguiente potencial ciclo.

El proceso de acumulación analizado aterriza de manera desigual en la geografía catalana. En primer lugar, presenta una mayor intensidad en los municipios más precarizados, incrementando así dicha precarización. En segundo lugar, lo hace en aquellos municipios donde durante el ciclo alcista la intensidad de construcción y la sobreexposición al crédito de las familias fue también mayor. Estos desequilibrios territoriales se reproducen a escala urbana, siendo los barrios más precarios aquellos que concentran procesos de desposesión de vivienda más intensos, retroalimentando la desigualdad.

\section{Referencias bibliográficas}

Aalbers, M. (2008). The financialization of home and the mortgage market crisis. Competition \& Change, 12(2), 148-166. doi: 10.1179/102452908X289802

Bermúdez, T. \& Trilla, C. (2014). Un parc d'habitatges de lloguer social. Una assignatura pendent a Catalunya. Dossier Catalunya Social. Propostes des del Tercer Sector, 39. http:// bit.ly/2xkwkSK

Bernardos, G. (2009). Creación y destrucción de la burbuja inmobiliaria en España. Revista ICE: Información Comercial Española. Número monográfico: La primera crisis global: procesos, consecuencias, medidas, (850), 23-40. http://bit.ly/2z1Z0Cq

Brenner, N. (2003). La formación de la ciudad global y el re-escalamiento del espacio del Estado en la Europa Occidental post-fordista. EURE, 29(86), 5-35. http://dx.doi. org/10.4067/S0250-71612003008600001

Burriel, E. (2014). El estallido de la burbuja inmobiliaria y sus efectos en el territorio. En J. M. Albertos \& J. L. Sánchez (coord.), Geografía de la crisis económica en España (pp. 101140). Valencia: Publicaciones de la Universidad de Valencia. 
Cano, G., Etxezarreta, A., Dol, K. \& Hoekstra, J. (2013). From housing bubble to repossessions: Spain compared to other West European countries. Housing Studies, 28(8), $1197-$ 1217. http://dx.doi.org/10.1080/02673037.2013.818622

Comisión Nacional de los Mercados y la Competencia (2015). Informe de la CNMC sobre las ayudas públicas en España - 2015 (IAP/CNMC/OOI/I 5). http://bit.ly/2fMUrTQ

Coq-Huelva, D. (2013). Urbanisation and financialisation in the context of a rescaling state: The case of Spain. Antipode, 45(5), 1213-1231. doi:10.1111/anti.12011

Donat, C. (2014). L'habitatge a la regió metropolitana de Barcelona durant el cicle immobiliari 1997-2006: una aproximació a partir de les necessitats residencials de la població. Tesis doctoral. Bellaterra: Universidad Autónoma de Barcelona. http://www.tdx.cat/ handle/10803/283519

Fernández Durán, R. (2009). El tsunami urbanizador español y global: sobre sus causas y repercusiones devastadoras, y la necesidad de prepararse para el previsible estallido de la burbuja inmobiliaria. Barcelona: Virus editorial.

García-Montalvo, J. (2008). De la quimera inmobiliaria al colapso financiero. Crónica de un desenlace anunciado. Barcelona: Antoni Bosch Editor.

Gotham, K. F. (2009). Creating liquidity out of spatial fixity: The secondary circuit of capital and the subprime mortgage crisis. International Journal of Urban and Regional Research, 32(2), 355-371. doi:10.1111/j.1468-2427.2009.00874.x

Gutiérrez, A. \& Delclòs, X. (2015). ¿ Hipertrofia inmobiliaria? Análisis de las pautas territoriales del boom e implicaciones del estallido de la burbuja en Cataluña. Cuadernos Geográficos de la Universidad de Granada, 54(1), 283-306. http://revistaseug.ugr.es/index.php/ cuadgeo/article/view/2527

Gutiérrez, A. \& Delclòs, X. (2016). The uneven distribution of evictions as new evidence of urban inequality: A spatial analysis approach in two Catalan cities. Cities, (58), 101108. http://dx.doi.org/10.1016/j.cities.2016.04.007

Gutiérrez, A. \& Delclòs, X. (2017). Geografía de la crisis inmobiliaria en Cataluña: Una lectura a partir de los desahucios por ejecución hipotecaria. Scripta Nova: Revista electrónica de Geografia y Ciencias Sociales, 21(557). http://revistes.ub.edu/index.php/ScriptaNova/ article/view/17734

Gutiérrez, A. \& Domènech, A. (2017a). The Spanish mortgage crisis: Evidence of the concentration of foreclosures in the most deprived neighbourhoods. Die Erde-Journal of the Geographical Society of Berlin, 148(1), 39-57. doi: 10.12854/erde-148-29

Gutiérrez, A. \& Domènech, A. (2017b). Geografía de los desahucios por ejecución hipotecaria en las ciudades españolas: evidencias a partir de las viviendas propiedad de la SAREB. Revista de Geografia Norte Grande, (67). En prensa.

Harvey, D. (1982). The limits to capital. Oxford: Basil Blackwell.

Harvey, D. (2003). The new imperialism. Oxford: Oxford University Press.

Hodkinson, S. (2012). The new urban enclosures. City: Analysis of Urban Trends, Culture, Theory, Policy, Action, 16(5), 500-518. http://dx.doi.org/10.1080/13604813.2012.7 09403

Ibáńez-Velasco, O. (2014). La titulización: el instrumento para la reactivación del crédito. Cuadernos de Información Económica, (242), 77-84. http://bit.ly/2hRHTz7 
López, I. \& Rodríguez, E. (2010). Fin de ciclo. Financiarización, territorio y sociedad de propietarios en la onda larga del capitalismo hispano (1959-2010). Madrid: Traficantes de Sueños. http://bit.ly/2y44C0I

López, I. \& Rodríguez, E. (2011). The Spanish model. New Left Review, (69), 5-28. https:// newleftreview.org/II/69/isidro-lopez-emmanuel-rodriguez-the-spanish-model

Méndez, R., Abad, L. \& Plaza, J. (2014). Geografía de las ejecuciones hipotecarias en España. Estudios de la Fundación $1^{\circ}$ de Mayo, (84), 1-41. http://www.1mayo.ccoo.es/nova/ files/1018/Estudio84.pdf

Méndez, R. \& Plaza, J. (2016). Crisis inmobiliaria y desahucios hipotecarios en España: una perspectiva geográfica. Boletín de la Asociación de Geógrafos Españoles, (71), 99-127. doi: $10.21138 /$ bage. 2276

Naredo, J. M. (2009). La cara oculta de la crisis. El fin del boom inmobiliario y sus consecuencias. Revista de Economía Critica, (7), 313-340. http://bit.ly/2ko85Sy

Naredo, J.M. (2010). El modelo inmobiliario español y sus consecuencias. Boletín $C F+S$, (44), 13-27. http://habitat.aq.upm.es/boletin/n44/ajnar.html

Oliver, J. (coord.) (2013). Informe sobre el sector immobiliari residencial a Espanya. Barcelona: Servei d'Estudis de Catalunya Caixa. http://bit.ly/2fNCdSe

Plataforma Auditoría Ciudadana de la Deuda (2103). La ilegitimidad de los Rescates a la Banca en el Estado español. Plataforma Auditoría Ciudadana de la Deuda. http:// auditoriaciudadana.net/documents/

Rullan, O. (2012). Urbanismo expansivo en el estado español: de la utopía a la realidad. En A. V. González \& J. A. Marco (eds.), Geografía, retos ambientales y territoriales (pp. 165209). Alicante: Universidad de Alicante.

Sevilla-Buitrago, A. (2015). Urbanismo, crisis y austeridad. Ciudades, (18), 31-48. http://bit. ly/1HhpYkH

Smith, N. (2012). La nueva frontera urbana. Ciudad revanchista y gentrificación. Madrid: Traficantes de Sueños. http://bit.ly/2y3qTLY

Valiño, V. (2013). Emergencia habitacional en el Estado español: La crisis de las ejecuciones hipotecarias y los desalojos desde una perspectiva de los derechos humanos. Barcelona: Observatorio DESC y Plataforma de Afectados por la Hipoteca. http://bit.ly/2yt03hm

Vives-Miró, S. \& Rullan, O. (2014). La vivienda en el tránsito de la reproducción ampliada del capital a la acumulación por desposesión en España. En AA.vv. (coord.), Territorios inconclusos y Sociedades Rotas (pp. 1-16). Madrid: Grupo de Geografía Urbana de la Asociación de Geógrafos Españoles.

Vives-Miró, S., González-Pérez, J.M . \& Rullan, O. (2015). Home dispossession: the uneven geography of evictions in Palma (Majorca). Die Erde - Journal of the Geographical Society of Berlin, 146(2-3), 113-126. doi:10.12854/erde-146-10 